\title{
Empirical Analysis on Influencing Factors of Purchase Intention of NEVs
}

\author{
Hua Bai ${ }^{1,2 *}$, Deqing Tan ${ }^{1}$ \\ ${ }^{1}$ School of Economics and Management, Southwest Jiaotong University, Chengdu, China \\ ${ }^{2}$ School of Economics and Management, Changchun Normal University, Changchun, China \\ Email: ^baihua@ccsfu.edu.cn
}

How to cite this paper: Bai, H., \& Tan, D. Q. (2021). Empirical Analysis on Influencing Factors of Purchase Intention of NEVs. Modern Economy, 12, 1835-1851. https://doi.org/10.4236/me.2021.1212095

Received: November 3, 2021

Accepted: December 17, 2021

Published: December 20, 2021

Copyright (c) 2021 by author(s) and Scientific Research Publishing Inc. This work is licensed under the Creative Commons Attribution International License (CC BY 4.0).

http://creativecommons.org/licenses/by/4.0/

\begin{abstract}
At present, the sales volume of new energy vehicle (NEV) in China is mainly driven by policies. If we want to truly realize the sales volume of NEV driven by market, we need to improve consumers' purchase intention. The key to improving consumers' purchase intention is to find the important influencing factors and formulate more targeted promotion strategies based on the important factors. Based on the construction of the influencing factor model of NEV purchase intention, this paper investigates 541 potential NEV consumers by means of "online network + offline sales outlets". Based on the survey data, this paper analyzes the main factors affecting NEV purchase intention by using binary logistic regression statistical method. The results show that age, education level and average annual household income have a significant impact on consumers' willingness to buy NEVs. Among respondents, consumers aged between 36 and 55, with college or undergraduate education and annual income between 160,000 and 250,000 yuan are more likely to buy NEVs. The regression results show that the quality of NEVs, charging convenience, after-sales service and surrounding user evaluation are the main factors affecting consumers' willingness to buy NEVs. Based on the research results, this paper puts forward countermeasures and suggestions for the development of NEV industry.
\end{abstract}

\section{Keywords}

Logistic Regression, NEVs, Purchase Intention, Influence Factor

\section{Introduction}

Since the implementation of the Chinese government's new energy vehicle subsidy retrogression policy in June 2019, the sales of new energy vehicles have been 
in a continuous decline. In November 2020, the general office of the State Council issued the new energy vehicle industry development plan (2021-2035), which proposed that by 2025, the sales of new energy vehicles will reach about $20 \%$ of the total sales of new vehicles. In order to achieve the goal of plan, carbon peak and carbon neutralization, China has accelerated the promotion of new energy vehicles (NEVs). Due to the vigorous promotion of the government, NEVs have performed well in logistics and public transportation. However, compared with traditional fuel vehicles, NEVs still have problems such as unstable quality, short cruising range, and inconvenient charging, so they perform poorly in private cars. In order to promote private purchase of NEVs, the government has actively introduced relevant fiscal and taxation policies and non-financial and taxation policies. Fiscal and taxation policies mainly include car purchase subsidies, purchase tax relief, charging facility construction subsidies, etc. Non-financial and taxation policies mainly include no waiting or short waiting time for vehicle licensing, no number limit for traffic in the city, etc. However, we can see from the current market performance that more private car consumers hold a wait-and-see attitude towards NEVs. The future development of NEV market should be driven by market rather than policy. Therefore, it is necessary to deeply study the NEVs purchase willingness, key influencing factors and influencing characteristics of potential consumers, so as to provide decision support for the government to formulate relevant policies and NEV enterprises to formulate market strategies. Therefore, firstly this paper summarizes the relevant research literature on consumers' willingness to buy NEVs, and analyzes the key factors affecting consumers' willingness; Secondly, based on the influencing factors summarized in the research results, a questionnaire was designed to obtain the survey data; Thirdly, based on the questionnaire data, the key influencing factors and influencing characteristics are obtained by binary logistic regression analysis; Finally, based on the research results, this paper gives conclusions and puts forward countermeasures and suggestions for the government and NEV enterprises.

\section{Literature Review}

Consumers' purchase intention of NEVs is affected by many factors. Scholars' research on the influencing factors mainly focuses on the quality of NEVs, using cost, after-sales service, charging infrastructure and consumer demographic characteristics. The relevant literature research is summarized as follows:

\subsection{Demographic Variables}

Demographic variables are the essential characteristics of consumers, including gender, age, education, income and other information. They are the decisive factor affecting consumers' purchase intention. Carley et al. (2013) investigated consumers' purchase intention of plug-in hybrid vehicles in major cities in the United States. The results show that consumers with higher education are more 
willing to buy electric vehicles. Knez et al. (2014) investigated the main factors affecting consumers' purchase intention of NEVs, and found that older respondents were more inclined to choose NEVs. Plötz et al. (2014) investigated and analyzed German electric vehicle consumers; it is found that the consumers who prefer to buy electric vehicles are men with high socio-economic status and long travel mileage every year. Hackbarth and Madlener (2013) analyzed the potential demand for consumers to choose NEVs and alternative fuel vehicles by using the discrete choice data of German stated preference. By applying the mixed logit model, it is found that well-educated young people are more willing to choose NEVs. Combined with the above literature, the demographic variables selected in this paper include: gender, age, education level and average annual family income.

\subsection{Consumers' Awareness of Environmental Protection}

Kahn (2007) found that environmentalists are more likely to buy hybrid vehicles than non-environmentalists by studying the buyers of hybrid vehicles in Los Angeles. Axsen and Kurani (2013) investigated 508 families in California and found that the respondents who are interested in electric vehicles are responsible, environmentally conscious and willing to support national development. Musti and Kockelman (2011) found that most respondents pay more attention to the impact of vehicle emissions on health and climate than the fuel cost savings of using NEVs. Therefore, consumers' awareness of environmental protection is an important factor affecting consumers' purchase intention of NEVs.

\subsection{Quality of NEVs}

A survey conducted by Deloitte Consulting in the United States shows that the reliability of electric vehicles is one of the primary considerations for consumers (Giffi et al., 2010). Ma et al. (2017) found that the quality of NEVs is still the bottleneck factor of the NEV industry, and the impact of technological progress on the diffusion of NEVs is greater than the economic subsidy policy. Therefore, the failure rate and battery attenuation of NEVs are important contents concerned by consumers.

\subsection{Charging Convenience}

At present, the level of NEV power supplement facilities cannot meet the needs of consumers to use NEV. The scarcity of power supplement facilities causes the phenomenon known as “customers' range anxiety" (Wang et al., 2019; Wang et al., 2017; Yu et al., 2021). Browne et al. (2012) analyzed the obstacles to the development of electric vehicles, among which the imperfect charging facilities are one of the obstacles. Zhu et al. (2016) believe that the construction level of charging facilities largely determines the market share of electric vehicles. Therefore, the perfection and convenience of charging supporting facilities are important factors affecting consumers' purchase intention of NEVs. 


\subsection{After-Sales Service}

Enterprises transmit product quality information to consumers through warranty services (Lei et al., 2017; Huang et al., 2021). In General, the consumers believe that the longer the warranty period, the more guaranteed the quality of the car (Bakshi et al., 2015). Therefore, warranty service is not only a legally mandatory service, but also a promotional measure (Qi et al., 2020). Guajardo et al. (2016) used empirical methods to analyze the impact of warranty period and after-sales service quality on American consumers' automobile purchase demand, and believe that after-sales service quality and warranty period have a compensation effect on product quality, and service quality and warranty period have a positive interactive impact on product demand. Therefore, the quality, response speed of after-sales service and warranty period are important factors affecting consumers' purchase of NEVs.

\subsection{Using Cost}

When buying a car, consumers will not only consider the performance of the car, but also consider the using cost after buying the car. Caperello and Kurani (2012) found that although the high purchase cost of electric vehicles hinders the promotion of electric vehicles, its lower using cost compared with traditional vehicles is the driving factor for the promotion of electric vehicles. Krupa et al. (2014) investigated 1000 residents in the United States and found that compared with the environmental benefits of electric vehicles, consumers pay more attention to the reduction of energy consumption cost of electric vehicles, and respondents who pay attention to the low energy consumption cost of electric vehicles are more likely to buy electric vehicles. Knez and Obrecht (2017) investigated the influencing factors affecting Slovenian consumers' purchase of electric vehicles and found that consumers are very concerned about the operating costs of electric vehicles. Li et al. (2020) research shows that for young consumers, almost all incentives to reduce operating costs or increase convenience will increase their adoption of electric vehicles. Therefore, the lower using cost of NEVs is a major factor to attract consumers to buy.

\subsection{Government Support Policy}

At the initial stage of the development of NEV industry, the government is the main driving force for the industrialization and marketization of NEVs. The government's policies on the new energy automobile industry will affect consumers' purchase intention of new energy automobiles (Du et al., 2018). Policies are mainly divided into fiscal and taxation policies and non-financial and taxation policies. Fiscal and taxation policies include car purchase subsidies, purchase tax relief, charging facilities subsidies and charging electricity subsidies. Non-financial and taxation policies include no waiting or short waiting time for vehicle licensing, free parking or unlimited travel, etc. Gallagher and Muehlegger (2011) believe that compared with other supporting policies, tax subsidies can 
promote consumers' purchase of NEVs. Lane and Potter (2007) investigated and analyzed the factors hindering the promotion of clean vehicles in the UK. The results show that the government's environmental protection regulations, oil price policy, purchase subsidies and strengthening infrastructure construction will affect the adoption rate of clean vehicles. Potoglou and Kanaroglou (2007) conducted an online questionnaire survey and analyzed it by using nested logit model. The results show that purchase tax reduction and cost reduction can effectively promote the use of electric vehicles, but the effects of some non-financial policies such as free parking and the use of special lanes are not obvious. Li et al. (2021) combined the potential Dirichlet allocation (LDA) theme model and econometric methods to explore the impact of the potential themes of many NEV policy documents on the promotion of NEVs at the urban level. It is found that the prevalence of promotion subsidy has an inverted U-shaped impact on the sales of NEVs, and the prevalence of production support has a significant positive impact. It is suggested to gradually eliminate procurement subsidies and increase investment in production support policies.

\subsection{Surrounding User Evaluation}

Zhang et al. (2011) investigated the factors most likely to affect Chinese consumers' choice of NEVs through empirical methods, and found that consumers' willingness to purchase NEVs is affected by the opinions of surrounding groups. Axsen et al. (2009) collected stated preference (SP) data and Revealed preference (RP) data from 535 Canadian and 408 Californian vehicle owners and found that "neighbor effect" has an impact on consumers' willingness to buy NEVs. Therefore, consumers' purchase intention is affected by surrounding users' evaluation and satisfaction with the use of NEVs.

\section{Models and Methods}

\subsection{Model Construction}

Firstly, consumers' own characteristics such as age, education level, income and other demographic variables and environmental awareness are internal factors that affect consumers' purchase intentions. Secondly, government support policies, the quality of NEVs, the convenience of charging, after-sales service, usage costs, and the evaluation of surrounding users are external factors that affect consumers' purchase intentions.

Therefore, based on the research results of the above scholars on consumers' purchase intention of NEVs, combined with expert interview and research, learn from (Mishra \& Malhotra, 2019) the method of model construction, this paper summarizes the influencing factors of consumers' purchase intention of NEVs, and constructs the influencing factor model of purchase intention of NEVs, as shown in Figure 1. The influencing factors in the model include consumers' own factors and external factors. Consumers' own factors include demographic variables and consumers' awareness of environmental protection. External 


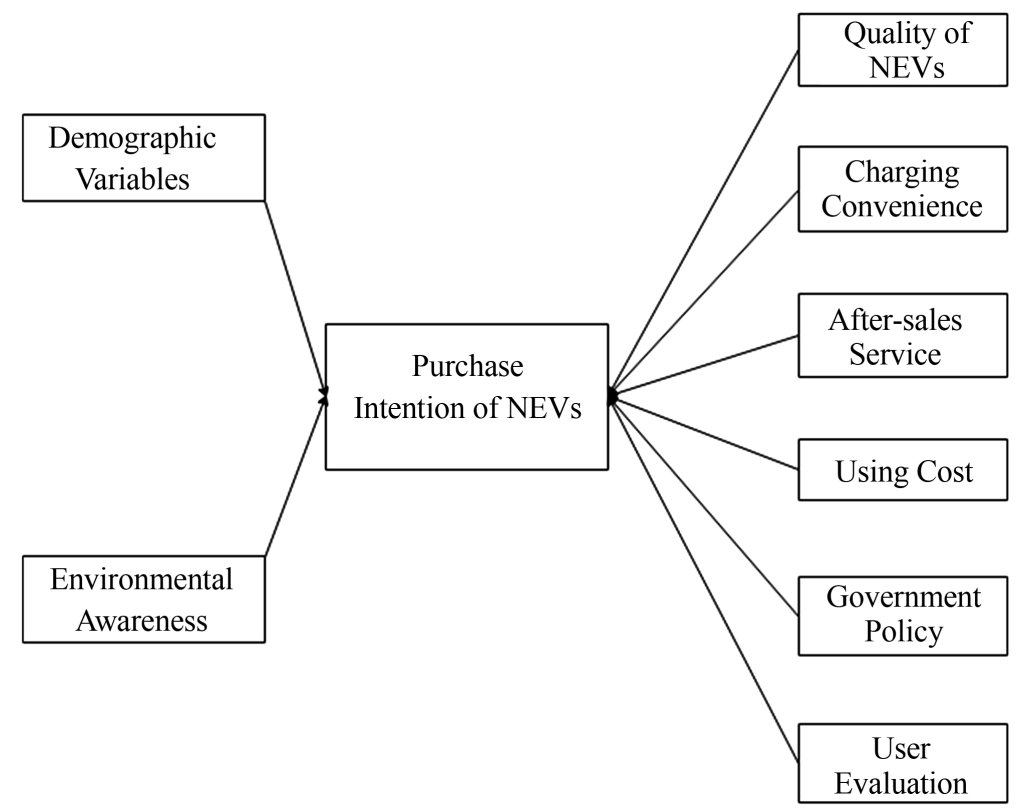

Figure 1. Model of factors affecting the purchase intention of NEVs.

factors include NEV quality, charging convenience, after-sales service, using cost, government support policies and user evaluation.

Based on the above research model, the "NEV Purchase Intention Questionnaire" is designed, which covers the various factors that affect consumers' purchase intention of NEVs in the model. After the questionnaire design was completed, some potential consumers and experts were surveyed and interviewed, and some topics were revised based on the interview results to form the final questionnaire.

The research object of this paper is private car consumers. The questionnaire adopts the random sampling survey method of "online + offline". The online questionnaire is in the form of online questionnaire. The offline surveys are randomly selected from visiting customers at major NEV sales outlets. A total of 600 questionnaires were issued, and 541 valid questionnaires were recovered. The effective response rate of the questionnaires reached $90.16 \%$. The questionnaire is divided into three parts. The first part is demographic variables, including gender, age, education level and income level. The second part is to measure the influencing factors of consumers' purchase intention of NEVs. The Likert 5-level scale is used. The scores 1 - 5 represent "completely disagree", "disagree", "general", "agree", "completely agree". The third part is to measure consumers' purchase intention of NEVs, 0 means unwilling to buy, 1 means willing to buy.

\subsection{Research Method}

In this paper, spss22.0 is used as a tool for data statistical analysis. The statistical analysis methods are as follows:

1) Descriptive statistical analysis: use frequency analysis to make descriptive statistics on demographic variables and influencing factor variables. 
2) Cross-contingency table analysis: base on the collected sample data, a crosscontingency table is generated, and the differences of different demographic variables in consumers' purchase intention are obtained. The Chi-square test is used to check whether there is correlation between each research variable and purchase intention based on the cross-continuation table.

3) Correlation analysis: this paper uses Pearson correlation coefficient to analyze the correlation between the influencing factors of purchase intention, in order to check whether there is multicollinearity between variables.

4) Binary logistic regression analysis: binary logistic regression is a variable analysis method to study the relationship between binary observation results and influencing factors. Therefore, this paper uses binary logistic regression to study the relationship between influencing factor variables and consumers' purchase intention.

\section{Data Analysis}

\subsection{Descriptive Statistics}

Table 1 lists the basic statistical characteristics of the demographic characteristic variables of the respondents. The proportion of males in the sample is $68.8 \%$, which is higher than the proportion of females. Respondents aged 36 - 55 accounted for $46.8 \%$ of the total number of samples, and 18 - 35 years old accounted for $37.9 \%$. These two age groups should be the main groups to buy private cars. Therefore, the data obtained from their survey are more convincing. From the perspective of education level, the educational level is above medium,

Table 1. Descriptive statistics of sample demographic variables.

\begin{tabular}{|c|c|c|c|}
\hline Variables & Item & Frequency & Percentage \\
\hline \multirow{2}{*}{ Gender } & Male & 372 & $68.8 \%$ \\
\hline & Female & 169 & $31.2 \%$ \\
\hline \multirow{3}{*}{ Age } & 18 - 35 years old & 205 & $37.9 \%$ \\
\hline & 36 - 55 years old & 253 & $46.8 \%$ \\
\hline & Over 56 years old & 83 & $15.3 \%$ \\
\hline \multirow{3}{*}{$\begin{array}{l}\text { Education } \\
\text { Level }\end{array}$} & $\begin{array}{l}\text { Technical secondary school, } \\
\text { High school or below }\end{array}$ & 171 & $31.6 \%$ \\
\hline & College or University & 335 & $61.9 \%$ \\
\hline & Master degree or above & 35 & $6.5 \%$ \\
\hline \multirow{5}{*}{$\begin{array}{c}\text { Average } \\
\text { Annual } \\
\text { Household } \\
\text { Income }\end{array}$} & Less than 100,000 yuan & 147 & $27.2 \%$ \\
\hline & $100,000-150,000$ yuan & 208 & $38.5 \%$ \\
\hline & $160,000-200,000$ yuan & 95 & $17.5 \%$ \\
\hline & $210,000-250,000$ yuan & 47 & $8.7 \%$ \\
\hline & More than 250,000 yuan & 44 & $8.1 \%$ \\
\hline
\end{tabular}


and the proportion of college and undergraduate is the highest, accounting for $61.9 \%$. These people have received more education and have their own views and opinions on things. Therefore, a large proportion of them in the sample will also add persuasion to the research results. The annual income level of the surveyed families is medium, and $64.7 \%$ of them have an annual income of 100,000 - 250,000 yuan.

\subsection{Reliability Analysis of Questionnaire}

Table 2 lists the basic statistical characteristics of various influencing factors of purchase intention of NEVs. It can be seen from the average value of each influencing factor that, except for product quality factors and charging convenience factors, the average values of other influencing factors are between 3.10 4.15. The mean value of government policy variables is the highest, indicating that consumers believe that the current government has given a lot of support to the promotion of NEVs. The higher mean value of the using cost variable indicates that most consumers clearly know that NEVs can save a lot of power supplement costs compared with fuel vehicles. The higher mean value of after-sales service variables indicates that new energy automobile companies give consumers more confidence through quality assurance services and extended warranty services. The mean value of user evaluation is also high, indicating that the users who use NEVs around the respondents have a good evaluation of NEVs. The low mean value of product quality variables indicates that consumers believe that NEVs are inferior to fuel vehicles in terms of quality stability. The low mean value of charging convenience variables indicates that the development of electric vehicles in terms of charging facilities is not perfect, and it is inconvenient for consumers to charge. At the same time, the respondents have a strong awareness of environmental protection. In this paper since the variables in the measurement scale are all measured with a Likert 5-level scale, the reliability of the scale is measured by Cronbach a coefficient. It is generally believed that the larger the Cronbach a coefficient, the higher the internal consistency of the scale.

Table 2. Reliability analysis.

\begin{tabular}{ccccc}
\hline Variables & Number of Questions & Mean & Variance & $\boldsymbol{\alpha}$ \\
\hline Environmental Awareness & 4 & 3.82 & 0.816 & 0.764 \\
Quality of NEVs & 5 & 2.84 & 1.124 & 0.794 \\
Charging Convenience & 4 & 1.66 & 0.983 & 0.834 \\
After-sales Service & 4 & 3.10 & 1.042 & 0.746 \\
Using cost & 3 & 3.72 & 0.83 & 0.678 \\
Government Policy & 4 & 4.15 & 0.735 & 0.805 \\
User Evaluation & 3 & 3.70 & 1.03 & 0.786 \\
$\quad$ Entire Scale & & & 0.764 & \\
\hline
\end{tabular}


If the value of $\alpha$ is greater than 0.70 indicates that the reliability of the scale is quite high. If the value of $\alpha$ is between 0.35 and 0.70 , the reliability of the scale is acceptable. If the value of $\alpha$ is below 0.35 means that the reliability is low and must be rejected. The results of reliability analysis of the scale are shown in Table 2. From the results of reliability analysis, the Cronbach a coefficients of each subscale and the entire scale are between $0.678-0.834$, indicating that the questionnaire has high reliability.

\subsection{Analysis on Purchase Intention of NEVs}

According to the survey of respondents' purchase intention of NEVs, more than $60 \%$ of respondents expressed their purchase intention. The results are shown in Table 3.

In order to further understand the difference of consumers' purchase intention of NEVs in demographic variables, this paper uses Cross-contingency table and Chi-square test to analyze the correlation between demographic variables and consumers' purchase intention. The results are shown in Table 4.

In terms of gender, $67.33 \%$ of those who choose not to buy NEVs are males, and this proportion rises to $69.62 \%$ when they choose to buy NEVs. Chi-square test results show that gender has no significant influence on the purchase intention of NEVs $\left(\chi^{2}=0.331 ; \mathrm{df}=1 ; p=0.657>0.05\right)$.

In terms of age, the proportion of people aged 18 - 35 who choose not to buy NEVs (46.53\%) is higher than the proportion of people who choose to buy NEVs (32.74\%).The proportions of people aged 36 - 55 and over 56 who are willing to buy NEVs (50.75\% and $16.51 \%$ ) are higher than that who are unwilling to buy NEVs. Chi-square test results show that age has a significant influence on the purchase intention of NEVs $\left(\chi^{2}=9.696 ; \mathrm{df}=2 ; p=0.012<0.05\right)$.

In terms of education level, the proportion of respondents with college education or above choosing to buy NEVs $(64.90 \%$ and $7.37 \%)$ is higher than that unwilling to buy. Chi-square test results show that education has a significant influence on the purchase intention of NEVs $\left(\chi^{2}=6.598 ; \mathrm{df}=2 ; p=0.032<0.05\right)$.

In terms of average annual household income, the proportion of respondents with an income of 100,000 - 150,000 yuan and more than 250,000 yuan who choose not to buy NEVs is higher than that of those who are willing to buy. The proportion of respondents with an income of less than 100,000 yuan, 160,000 200,000 yuan and 200,000 - 250,000 yuan who choose to buy NEVs is higher than that of those who do not want to buy. Chi-square test results show that

Table 3. Purchase Intention of NEVs.

\begin{tabular}{cccc}
\hline Dependent Variable & Option & Frequency & Percentage \\
\hline Are you willing to buy NEVs? & No & 202 & $37.34 \%$ \\
Valid & Yes & 339 & $62.66 \%$ \\
& & 541 & $100 \%$
\end{tabular}


Table 4. Cross-contingency table of demographic variables and purchase intention.

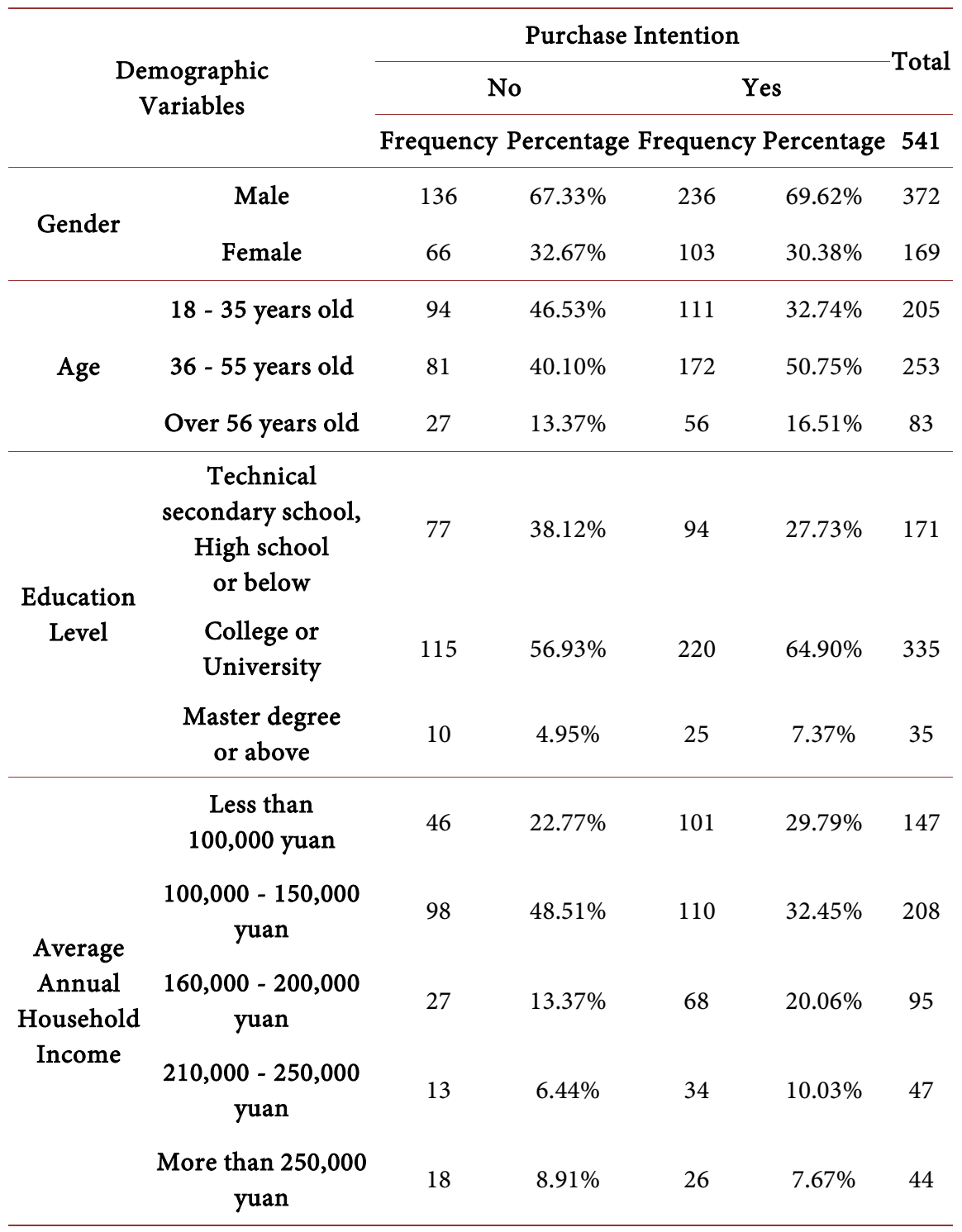

average annual household income has a significant influence on the purchase intention of NEVs $\left(\chi^{2}=16.097 ; \mathrm{df}=4 ; p=0.002<0.01\right)$.

Through the Cross-contingency table analysis and Chi-square test, we can get the relationship between demographic variables and purchase intention of NEVs: gender has no significant influence on purchase intention of NEVs, while age, education level and average annual household income have significant influence on purchase intention of NEVs.

Through the above analysis, we can draw a conclusion that consumers over the age of 36 , with college or university education and an average annual family income of 160,000 - 250,000 yuan are more willing to buy NEVs; Consumers under the age of 35 , with a high school or technical secondary school education and an average annual family income of 100,000 - 150,000 are more reluctant to buy NEVs. 


\section{Logistic Regression Analysis}

Through the analysis in the previous section, we get the conclusion that the questionnaire has high reliability, and get the demographic characteristics of potential consumers of NEVs. In order to further study the relationship between each influencing factor variable and the purchase intention of NEVs and the degree of influence, this paper uses spss22.0 to conduct binomial logistic regression estimation analysis on the purchase intention.

\subsection{Variable Correlation Test}

It is necessary to test whether there is a multicollinearity problem between the independent variables before the logistic regression analysis. The Pearson correlation coefficient of the research variables is calculated by SPSS software to determine the linear correlation between the variables. The greater the absolute value of the correlation coefficient, the stronger the correlation. Generally, the correlation of variables is judged by the following value range: the correlation coefficient of 0.8 - 1.0 indicates very strong correlation, 0.6 - 0.8 indicates strong correlation, 0.4 - 0.6 indicates medium correlation, 0.2 - 0.4 indicates weak correlation, and $0.0-0.2$ indicates very weak correlation or no correlation. High correlation between variables may lead to multicollinearity problems. Table 5 shows the Pearson correlation coefficient matrix of variables. The correlation coefficients between variables are less than 0.5 , indicating that the correlation between variables is low and there is no multicollinearity problem.

\subsection{Logistic Regression Equation}

Suppose $P$ represents the probability that consumers are willing to buy NEVs, and $1-P$ represents the probability that consumers are unwilling to buy NEVs. The binary logistic regression model is

$$
\operatorname{logit} P=\ln \left[\frac{P}{1-P}\right]=B_{0}+B_{1} X_{1}+B_{2} X_{2}+\cdots+B_{n} X_{n}
$$

Table 5. Variable correlation matrix.

\begin{tabular}{|c|c|c|c|c|c|c|c|}
\hline Variable & $\begin{array}{c}\text { Environmental } \\
\text { Awareness }\end{array}$ & $\begin{array}{l}\text { Quality } \\
\text { of NEVs }\end{array}$ & $\begin{array}{l}\text { Charging } \\
\text { Convenience }\end{array}$ & $\begin{array}{l}\text { After-Sales } \\
\text { Service }\end{array}$ & $\begin{array}{l}\text { Using } \\
\text { Cost }\end{array}$ & $\begin{array}{c}\text { Government } \\
\text { Policy }\end{array}$ & $\begin{array}{c}\text { User } \\
\text { Evaluation }\end{array}$ \\
\hline Environmental Awareness & 1 & & & & & & \\
\hline Quality of NEVs & $0.338^{\star *}$ & 1 & & & & & \\
\hline Charging Convenience & $0.168^{\star *}$ & $0.264^{\star *}$ & 1 & & & & \\
\hline After-Sales Service & $0.174^{\star *}$ & $0.468^{*}$ & $0.228^{\star *}$ & 1 & & & \\
\hline Using Cost & $0.156^{\star *}$ & $0.413^{\star *}$ & $0.189^{* *}$ & $0.367^{\star *}$ & 1 & & \\
\hline Government Policy & $0.186^{\star *}$ & $0.335^{\star}$ & $0.442^{\star *}$ & $0.172^{*}$ & $0.166^{* *}$ & 1 & \\
\hline User Evaluation & $0.167^{\star *}$ & $0.283^{\star *}$ & $0.214^{*}$ & $0.202^{\star *}$ & $0.175^{\star *}$ & $0.143^{\star \star}$ & 1 \\
\hline
\end{tabular}

${ }^{*}$ indicates a significant correlation at the 0.01 level (bilateral). ${ }^{*}$ indicates a significant correlation at the 0.05 level (bilateral). 
The independent variables in the model are seven influencing factors: consumers' awareness of environmental protection, quality of NEVs, charging convenience, after-sales service, using cost, government support policy and users' evaluation. In this paper, binary logistic regression is carried out by SPSS software to obtain the influence characteristics and degree of various influencing factors on the purchase intention of NEVs. The model obtains a log-likelihood value of 132.3 with only the intercept term, and the Chi-square value of the final model is 32.722 , with a significance of 0.000 . It can be seen that the final model is more significant. Meanwhile, the $\mathrm{p}$ value corresponding to Pearson chi-square statistics and deviation chi-square statistics is greater than 0.05, and the assumption that the actual value is consistent with the predicted value cannot be rejected, indicating that the model has good goodness of fit. The results of binary logistic regression analysis are shown in Table 6 . When the significance of each statistic is less than 0.05 , the regression effect can be considered significant, indicating that there is a causal relationship between the influencing factor indicators and the purchase intention of NEVs. It can be seen from Table 6 that the influencing factors with significance less than 0.05 include the quality of NEVs, charging convenience, after-sales service and user evaluation.

According to the regression results in Table 6, the logistic regression equation is:

$$
\text { logit } P=\ln \left[\frac{P}{1-P}\right]=-2.112+0.486 X_{1}+0.396 X_{2}+0.285 X_{3}+0.323 X_{4}
$$

where $X_{1}$ represents the quality of NEVs, $X_{2}$ represents charging convenience, $X_{3}$ represents after-sales service, $X_{4}$ represents user evaluation.

\subsection{Discuss}

The variables regression coefficients of quality of NEV, charging convenience, after-sales service and user evaluation are positive, indicating that when the values of these four variables increase, consumers' purchase intention of NEVs will increase. Among these four factors, the factor that has the greatest influence on

Table 6. Binary logistic regression results.

\begin{tabular}{ccccccc}
\hline Independent Variable & B & S.E. & Wald & df & Sig. & Exp (B) \\
\hline Intercept & -2.112 & 0.154 & 188.082 & 1 & 0.000 & \\
Environmental Awareness & 0.015 & 0.090 & 0.028 & 1 & 0.144 & 1.015 \\
Quality of NEVs & 0.486 & 0.163 & 8.890 & 1 & 0.008 & 1.626 \\
Charging Convenience & 0.396 & 0.176 & 5.063 & 1 & 0.012 & 1.486 \\
After-Sales Service & 0.285 & 0.142 & 4.028 & 1 & 0.021 & 1.330 \\
$\quad$ Using Cost & -0.069 & 0.092 & 0.5625 & 1 & 0.123 & 1.071 \\
Government Policy & 0.054 & 0.145 & 0.139 & 1 & 0.216 & 1.055 \\
User Evaluation & 0.323 & 0.153 & 4.456 & 1 & 0.018 & 1.381 \\
\hline
\end{tabular}


consumers' purchase intention of NEVs is the quality of NEVs, followed by charging convenience, user evaluation and after-sales service. We would analyze the influences of the above four variables on consumers' purchase intention of NEVs as following.

1) The regression coefficient of the quality variable of NEVs is positive, indicating that the better the quality of NEVs, the more likely consumers are to buy NEVs. When other variables are controlled, for each unit of increase in the quality of NEVs, the probability ratio of consumers who are willing to buy NEVs ( $Y$ $=1)$ to consumers who are unwilling to buy NEVs $(Y=0)$ will become 1.626 times the original. Compared with traditional fuel vehicles, the production technology of NEVs is relatively immature and the quality is not stable. NEVs are high priced durable goods, and consumers are more sensitive to their quality. Therefore, R \& D investment should be increased to improve the product performance and quality stability of NEVs.

2) The regression coefficient of charging convenience variable is positive, indicating that the more convenient the charging of NEVs, the more likely consumers are to buy NEVs. When other variables are controlled, for each unit of increase in charging convenience of NEVs, the probability ratio of consumers willing to buy NEVs $(Y=1)$ to consumers unwilling to buy NEVs $(Y=0)$ will become 1.486 times the original. The charging convenience of NEVs includes two aspects: one is the large number and reasonable layout of charging facilities, and the other is the short charging time. Therefore, while continuously increasing the ratio of vehicles to piles, reasonable layout of charging facilities is being carried out. In addition, we try to use the power supplement mode of "replacement-based and charging-assisted" to greatly shorten the power supplement time and eliminate consumers' "charging anxiety".

3) The regression coefficient of user evaluation variable is positive, indicating that the higher the user's evaluation of NEVs, the more likely consumers are to buy NEVs. When other variables are controlled, for each unit of increase in users' positive evaluation of NEVs, the probability ratio of consumers who are willing to buy NEVs $(Y=1)$ to consumers who are unwilling to buy NEVs ( $Y=$ 0 ) will become 1.381 times the original. Consumers' purchase intention is affected by existing users' evaluation of NEVs, especially their friends, colleagues and family members. Therefore, when promoting NEVs, we should not only pay attention to the communication of traditional media, but also pay attention to the role of social networks.

4) The regression coefficient of after-sales service variable is positive, indicating that the better the after-sales service of NEVs, the more likely consumers are to buy NEVs. When other variables are controlled, for each unit of increase in charging convenience of NEVs, the probability ratio of consumers who are willing to buy NEVs $(Y=1)$ to consumers who are unwilling to buy NEVs $(Y=0)$ will become 1.330 times the original. After-sales service includes content, quality and warranty period of after-sales service. Therefore, NEV enterprises should continuously improve the after-sales service quality, speed up the service re- 
sponse speed and appropriately extend the warranty period, to relieve consumers' "quality anxiety" and enhance consumer confidence.

In addition, it should be noted that the overall government support policy variables are not significant. On the one hand, the incentive effect of financial subsidies is gradually declining, on the other hand, the sample size of Beijing, Shanghai, Guangzhou and Shenzhen is small. Through further observation, it is found that for the respondents in Beijing, Shanghai, Guangzhou and Shenzhen, government support policies such as license no waiting, parking preference and unlimited travel have a significant impact on their purchase intention.

\section{Conclusion}

Through this paper, we can find that age, education and income will significantly affect consumers' purchase intention of NEVs. NEVs are new products, and consumers have perceived risks to their quality, charging convenience and battery attenuation. Generally speaking, young people are more willing to try new things and have the spirit of adventure, but in this study, older (not elderly) consumers with high level of education and upper middle income are more inclined to buy NEVs than young consumers. Firstly, it takes a long time to charge NEVs (generally 6 - 8 hours), young people have a fast pace of life and work, and use cars randomly, so they are more sensitive to time. While the older (not elderly) consumers' workplace and pace of life are relatively stable, and the driving time and distance are more fixed, so they can reasonably plan the charging time. Second, the main advantage of NEVs over fuel vehicles lies in the lower using cost. The advantage of low electricity prices is more prominent especially when fuel prices are rising steadily. The older (not elderly) consumers are more sensitive to the using cost than younger consumers. Therefore, we should improve the construction level of charging facilities as soon as possible, and shorten the charging time to attract young people to buy NEVs.

Based on the above analysis, the government should speed up and improve the construction of charging facilities, focus on strengthening the layout planning of charging facilities and promote the battery replacement model as soon as possible. In addition, in cities such as Beijing, Shanghai, Guangzhou, and Shenzhen, which have more restrictions on the listing and rights of roads of fuel vehicles, parking difficulties and high costs, we should continue to strengthen the support for non-financial and taxation measures for NEVs. NEV companies should focus on their own core technologies, continuously improve vehicle quality, improve after-sales service systems, and improve existing user satisfaction, and increase potential consumers' purchase intention from both the high quality of their products and the good reputation of users.

\section{Funding}

Humanities and Social Sciences Foundation Project of Changchun Normal University [2016(004)]. 


\section{Conflicts of Interest}

The authors have no conflicts of interest to declare that are relevant to the content of this article.

\section{Authors' Contributions}

Hua Bai: writing original draft, review and editing; Deqing Tan: Methodology and supervision. All authors have approved the manuscript.

\section{References}

Axsen, J., \& Kurani, K. S. (2013). Hybrid, Plug-In Hybrid, or Electric-What Do Car Buyers Want? Energy Policy, 61, 532-543. https://doi.org/10.1016/j.enpol.2013.05.122

Axsen, J., Mountain, D. C., \& Jaccard, M. (2009). Combining Stated and Revealed Choice Research to Simulate the Neighbor Effect: The Case of Hybrid-Electric Vehicles. Resource and Energy Economics, 31, 221-238.

https://doi.org/10.1016/j.reseneeco.2009.02.001

Bakshi, N., Kim, S., \& Savva, N. (2015). Signaling New Product Reliability with After-Sales Service Contracts. Management Science, 61, 1812-1829.

https://doi.org/10.1287/mnsc.2014.2029

Browne, D., O’Mahony, M., \& Caulfield, B. (2012). How Should Barriers to Alternative Fuels and Vehicles Be Classified and Potential Policies to Promote Innovative Technologies Be Evaluated? Journal of Cleaner Production, 35, 140-151.

https://doi.org/10.1016/j.jclepro.2012.05.019

Caperello, N. D., \& Kurani, K. S. (2012). Households' Stories of Their Encounters with a Plug-In Hybrid Electric Vehicle. Environment and Behavior, 44, 493-508. https://doi.org/10.1177/0013916511402057

Carley, S., Krause, R. M., Lane, B. W., \& Graham, J. D. (2013). Intent to Purchase a Plug-In Electric Vehicle: A Survey of Early Impressions in Large US Cites. Transportation Research Part D: Transport and Environment, 18, 39-45. https://doi.org/10.1016/j.trd.2012.09.007

Du, H., Liu, D., Sovacool, B. K., Wang, Y., Ma, S., \& Li, R. Y. M. (2018). Who Buys New Energy Vehicles in China? Assessing Social-Psychological Predictors of Purchasing Awareness, Intention, and Policy. Transportation Research Part F: Traffic Psychology and Behaviour, 58, 56-69. https://doi.org/10.1016/j.trf.2018.05.008

Gallagher, K. S., \& Muehlegger, E. (2011). Giving Green to Get Green? Incentives and Consumer Adoption of Hybrid Vehicle Technology. Journal of Environmental Economics and Management, 61, 1-15. https://doi.org/10.1016/j.jeem.2010.05.004

Giffi, C., Hill, R., \& Garder, M. (2010). A Customer View of Electric Vehicle Mass Adoption in the US Automotive Market. Deloitte Consulting LLC.

Guajardo, J. A., Cohen, M. A., \& Netessine, S. (2016). Service Competition and Product Quality in the U. S. Automobile Industry. Management Science, 62, 1860-1877. https://doi.org/10.1287/mnsc.2015.2195

Hackbarth, A., \& Madlener, R. (2013). Consumer Preferences for Alternative Fuel Vehicles: A Discrete Choice Analysis. Transportation Research Part D: Transport and Environment, 25, 5-17. https://doi.org/10.1016/j.trd.2013.07.002

Huang, H., Liu, F., \& Zhang, P. (2021). To Outsource or Not to Outsource? Warranty Service Provision Strategies Considering Competition, Costs and Reliability. International Journal of Production Economics, 242, Article ID: 108298. 
https://doi.org/10.1016/j.ijpe.2021.108298

Kahn, M. E. (2007). Do Greens Drive Hummers or Hybrids? Environmental Ideology as a Determinant of Consumer Choice. Journal of Environmental Economics and Management, 54, 129-145. https://doi.org/10.1016/j.jeem.2007.05.001

Knez, M., \& Obrecht, M. (2017). Policies for Promotion of Electric Vehicles and Factors Influencing Consumers' Purchasing Decisions of Low Emission Vehicles. Journal of Sustainable Development of Energy, Water and Environment Systems, 5, 151-162. https://doi.org/10.13044/j.sdewes.d5.0139

Knez, M., Jereb, B., \& Obrecht, M. (2014). Factors Influencing the Purchasing Decisions of Low Emission Cars: A Study of Slovenia. Transportation Research Part D: Transport and Environment, 30, 53-61. https://doi.org/10.1016/j.trd.2014.05.007

Krupa, J. S., Rizzo, D. M., Eppstein, M. J., Brad Lanute, D., Gaalema, D. E., Lakkaraju, K., \& Warrender, C. E. (2014). Analysis of a Consumer Survey on Plug-in Hybrid Electric Vehicles. Transportation Research Part A: Policy and Practice, 64, 14-31. https://doi.org/10.1016/j.tra.2014.02.019

Lane, B., \& Potter, S. (2007). The Adoption of Cleaner Vehicles in the UK: Exploring the Consumer Attitude-Action Gap. Journal of Cleaner Production, 15, 1085-1092. https://doi.org/10.1016/j.jclepro.2006.05.026

Lei, Y., Liu, Q., \& Shum, S. (2017). Warranty Pricing with Consumer Learning. European Journal of Operational Research, 263, 596-610. https://doi.org/10.1016/j.ejor.2017.06.024

Li, J., Jiao, J., Xu, Y., \& Chen, C. (2021). Impact of the Latent Topics of Policy Documents on the Promotion of New Energy Vehicles: Empirical Evidence from Chinese Cities. Sustainable Production and Consumption, 28, 637-647. https://doi.org/10.1016/j.spc.2021.06.023

Li, L., Wang, Z., Chen, L., \& Wang, Z. (2020). Consumer Preferences for Battery Electric Vehicles: A Choice Experimental Survey in China. Transportation Research Part D: Transport and Environment, 78, Article ID: 102185.

https://doi.org/10.1016/j.trd.2019.11.014

Ma, S., Fan, Y., \& Feng, L. (2017). An Evaluation of Government Incentives for New Energy Vehicles in China Focusing on Vehicle Purchasing Restrictions. Energy Policy, 110, 609-618. https://doi.org/10.1016/j.enpol.2017.07.057

Mishra, S., \& Malhotra, G. (2019). Is India Ready for E-MOBILITY? An Exploratory Study to Understand e-Vehicles Purchase Intention. Theoretical Economics Letters, 9, 376-391. https://doi.org/10.4236/tel.2019.92027

Musti, S., \& Kockelman, K. M. (2011). Evolution of the Household Vehicle Fleet: Anticipating Fleet Composition, PHEV Adoption and GHG Emissions in Austin, Texas. Transportation Research Part A: Policy and Practice, 45, 707-720. https://doi.org/10.1016/j.tra.2011.04.011

Plötz, P., Schneider, U., Globisch, J., \& Dütschke, E. (2014). Who Will Buy Electric vehicles? Identifying Early Adopters in Germany. Transportation Research Part A: Policy and Practice, 67, 96-109. https://doi.org/10.1016/j.tra.2014.06.006

Potoglou, D., \& Kanaroglou, P. S. (2007). Household Demand and Willingness to Pay for Clean Vehicles. Transportation Research Part D: Transport and Environment, 12, 264-274. https://doi.org/10.1016/j.trd.2007.03.001

Qi, Y., Wu, J., Zhao, T., Sun, Y., \& Wu, B. (2020). Game Theoretic Analysis of After-Sales Service in Two-Echelon Supply Chain with Warranty Sensitive Demand. Mathematical Problems in Engineering, 2020, Article ID: 2317246.

https://doi.org/10.1155/2020/2317246 
Wang, N., Tang, L., \& Pan, H. (2019). A Global Comparison and Assessment of Incentive Policy on Electric Vehicle Promotion. Sustainable Cities and Society, 44, 597-603. https://doi.org/10.1016/j.scs.2018.10.024

Wang, S., Li, J., \& Zhao, D. (2017). The Impact of Policy Measures on Consumer Intention to Adopt Electric Vehicles: Evidence from China. Transportation Research Part A: Policy and Practice, 105, 14-26. https://doi.org/10.1016/j.tra.2017.08.013

Yu, Y., Zhou, D., Zha, D., \& Wang, Q. (2021). Joint Optimization of Charging Facility Investment and Pricing in Automobile Retail Supply Chain and Coordination. Computers \& Industrial Engineering, 156, Article ID: 107296.

https://doi.org/10.1016/j.cie.2021.107296

Zhang, Y., Yu, Y., \& Zou, B. (2011). Analyzing Public Awareness and Acceptance of Alternative Fuel Vehicles in China: The Case of EV. Energy Policy, 39, 7015-7024.

https://doi.org/10.1016/j.enpol.2011.07.055

Zhu, L., Lu, H., Zhang, Q., Li, H., Pan, X., Wang, G., \& Li, Y. (2016). Application of Crowdfunding on the Financing of EV's Charging Piles. Energy Procedia, 104, 336-341. https://doi.org/10.1016/j.egypro.2016.12.057 